\title{
O SISTEMA DE EDUCAÇÃO SUPERIOR MUNDIAL: ENTRE A INTERNACIONALIZAÇÃO ATIVA E PASSIVA
}

\author{
MaNolita CoRreia Lima* \\ Carolina Machado Saraiva de Albuquerque Maranhão**
}

Recebido em: 17 de agosto de 2009 Aprovado em: 01 de setembro de 2009

*Prof ${ }^{a}$ titular da Escola Superior de Propaganda e Marketing. E-mail: mclima@espm.br

**Doutoranda em Administração do Centro de Pós-Graduação e Pesquisas em Administração - UFMG, bolsista da CAPES. E-mail: carola.maranhao@gmail.com

Resumo: Levando em conta as especificidades que singularizam a internacionalização da educação, o objetivo deste texto reside em definir o conceito de internacionalização ativa e passiva no universo da Educação para em seguida aplicá-lo no aprofundamento de questões pertinentes à mobilidade estudantil. Inicialmente discutir-se-á a mobilidade no âmbito mundial, levando em conta dados relativos aos principais países receptores e emissores de estudantes, e finalmente situar-se-á o fenômeno entre os países latino-americanos. A discussão permitirá argumentar que, limitada a poucos países, a internacionalização ativa se presta a criar condições favoráveis à emergência de uma internacionalização hegemônica (DALE, 2004; e outros). Tais condições contribuem para o agravamento do que Boaventura de Sousa Santos (2002), António Teodoro (2003) e Roger Dale (2004) nomeiam de globalização hegemônica. Neste contexto, os desequilíbrios regionais se alargam na medida em que há flagrante descompasso entre os ativos conquistados nos países centrais e periféricos. As fontes de materiais explorados na fundamentação das idéias serão de caráter bibliográfico e documental. A pesquisa documental se valerá, predominantemente, de relatórios de pesquisas realizadas em âmbito mundial, com o suporte de organismos multilaterais - Institut de Statistique (UNESCO, 2007, 2006, 2005, 2004, 2003); International Institute for Education (OCDE, 2007; 2006a; 2006b; 2005; 2004); Centre pour la Recherche et l'Innovation dans l'Enseignement (OCDE, 2004); Banque Mondial/OCDE (2004; 2005); Associação Internacional de Universidades (UNESCO, 2003). Os dados selecionados serão interpretados com o suporte de diversificado referencial teórico.

Palavras-chave: Internacionalização da educação superior. Internacionalização ativa. Internacionalização passiva.

\section{THE WORLDWIDE HIGHER EDUCATION SYSTEM: BETWEEN ACTIVE AND PASSIVE INTERNATIONALIZATION}

\begin{abstract}
Considering the specificities of education internationalization, the purpose of this paper is to present the concepts of active and passive internationalization and apply them to pertinent questions regarding student mobility. Initially mobility at a worldwide level will be discussed, considering data from the main countries which "import" and "export" students. Finally, the phenomenon among the Latin American countries will be placed as well. Results suggest that, limited to a few countries, active internationalization creates conditions favorable to the emergence of an hegemonic internationalization (DALE, 2004; and others). Such conditions contribute to the aggravation of what Boaventura de Sousa Santos (2002), António Teodoro (2003) and Roger Dale (2004) denominate as hegemonic globalization. In this context, the regional unbalances widen since there are great differences in the human capital received by central and peripheral countries. The sources of materials explored will be bibliographical and documentary. The documentary research will predominantly use research reports carried throughout a world-wide scope, with the support of multilateral institutions - Institut de Statistique (UNESCO, 2007, 2006, 2005, 2004, 2003); International Institute will be Education (OCDE, 2007; 2006a; 2006b; 2005; 2004); Centre pour la Recherche et l'Innovation dans l'Enseignement (OCDE, 2004); Banque Mondial/OCDE (2004; 2005); International association of University (UNESCO, 2003). The selected data will be interpreted with the support of diversified bibliographical references.
\end{abstract}

Key words: University education. Internalization. Active internalization. Passive internalization. 


\section{Introdução - definição dos objetivos e dos recursos metodológicos}

Ao desenvolver discussão de natureza conceptual acerca de termos (internacional, transnacional, transfronteiriço, e global) recorrentemente utilizados para expressar a idéia de internacionalização da educação, Knight (2005, p. 12-45) propõe uma definição técnica que leva em conta aspectos genéricos e por isso capazes de respeitar especificidades existentes nos diversos sistemas educativos e múltiplas culturas acadêmicas, encontradas nos distintos países. Para a autora (2005, p. 22), "l'internationalisation à l'échelle du pays/du secteur/de l'établissement désigne le processus que consiste à intégrer une dimension internationale, interculturelle ou mondiale aux finalités, aux fonctions ou à l'organisation de l'enseignement postsecundaire." Apesar de definir os termos coopération internationale verticale e horizontale, Knight (2005, p. 15) não faz uso dos conceitos de internacionalização ativa e passiva, mesmo ciente de que o fenômeno está orientado por diversos objetivos, envolve múltiplos fornecedores, não ocorre do mesmo modo em todos os países, tampouco atinge resultados semelhantes. Contudo, a literatura que trata do processo de internacionalização em determinados áreas/setores de atividade tem utilizado os supracitados conceitos: Brandão (2006), referindo-se à internacionalização passiva das Ciências Sociais latino-americana; Lourenço (2006), reportandose ao setor siderúrgico; Roselino e Diegues (2006) investigando a indústria de software; Santos, (2004) estudando o setor de comunicação; Brandão (1994) referindo-se ao setor de telecomunicação etc.

Levando em conta as especificidades que singularizam a internacionalização da educação, o objetivo do texto reside em definir o conceito de internacionalização ativa e passiva no universo da Educação para em seguida aplicá-lo no aprofundamento de questões pertinentes à mobilidade estudantil. Inicialmente discutir-se-á a mobilidade no âmbito mundial, levando em conta dados relativos aos principais países receptores e emissores de estudantes, e finalmente situar-se-á o fenômeno entre os países latino-americanos. O raciocínio permitirá argumentar que enquanto a internacionalização ativa está limitada a poucos países, se presta a criar condições que favorecem a emergência de uma espécie de internacionalização hegemônica (DALE, 2004; TEODORO, 2003; SANTOS, 2002) e por isso mesmo capaz de exercer expressiva influência sobre a organização do sistema mundial de educação superior; a internacionalização passiva está presente na maioria dos países semiperiféricos e periféricos da economia-mundo e seus resultados tendem a responder mais a interesses comerciais do que culturais. Frente a esta constatação, os autores resistem a uma 
leitura apologética que insiste em naturalizar os efeitos da globalização na Educação, adotando uma abordagem mais crítica do fenômeno por entender que parte do atual processo de internacionalização tende a contribuir para o comprometimento de uma educação eminentemente republicana.

As fontes de materiais explorados na fundamentação das idéias serão de caráter bibliográfico e documental. Apesar de o tema ainda suscitar pouco interesse entre os acadêmicos brasileiros, a literatura internacional não é modesta - da década de 90 em diante observa-se expressiva preocupação com as diversas faces que o fenômeno apresenta, desde a acadêmica até a cultural, política e econômica (BROUILLETTE; FORTIN, 2004, p. 5). A pesquisa documental se valerá, predominantemente, de relatórios de pesquisas realizadas com o suporte de organismos multilaterais - Institut de Statistique (UNESCO, 2007, 2006, 2005, 2004, 2003); International Institute for Education (OCDE, 2007; 2006a; 2006b; 2005; 2004); Centre pour la Recherche et l'Innovation dans l'Enseignement (OCDE, 2004); Banque Mondial/OCDE (2005); Associação Internacional de Universidades (UNESCO, 2003). Os dados selecionados serão interpretados com o suporte de diversificado referencial teórico.

\section{Discussão de caráter conceptual \\ - a internacionalização ativa e passiva}

No âmbito do senso comum, enquanto o termo ativo sugere a formação de uma visão positiva, associada à inteligência daquele que exerce ação direta sobre algo ou alguém com a intenção deliberada de gerar resultados previamente estabelecidos; o termo passivo, ao contrário, assume conotação negativa porque associada à subalternidade, à dependência daquilo ou daquele que é objeto de determinada ação. Em qual contexto situar os conceitos de internacionalização ativa e passiva, no universo da educação? Na contemporaneidade, a internacionalização da educação tem evoluído da mobilidade de pessoas (manifestação recorrente) para a circulação de programas, abertura de campi (branch-campus), e instalação de instituições fora do país de origem (KNIGHT, 2005, p. 21-22):

a) Consumo dos serviços educacionais no exterior, envolvendo migração de estudantes, professores, pesquisadores, representantes da administração universitária, interessados em realizar cursos de curta (educação continuada) e/ou longa duração (cursos de formação - graduação, mestrado e doutorado), em instituições localizadas fora do país de origem. 
b) Prestação de serviços educacionais no exterior, envolvendo a mobilidade de profissionais (técnicos, professores, pesquisadores), com reconhecida expertise, para realização de serviço temporário em outro território, na condição de palestrante, professor visitante, pesquisador, consultor etc.

c) Oferta transfronteiriça de serviço (cross-border supply) envolvendo a mobilidade de programas de formação ou capacitação organizados na forma presencial ou à distância, aplicação de testes, implantação de sistemas de avaliação etc.

d) Presença comercial envolvendo a mobilidade da organização prestadora de serviço e sua instalação em país(es) interessado(s) em estimular a formação de joint-ventures com instituições locais ou de franquias (estratégia conhecida entre as escolas de línguas, por exemplo).

Enquanto a inserção internacional do setor educacional, existente nos países centrais, se manifesta de forma ativa, isto é, com a implantação de políticas de Estado voltadas para a atração e acolhimento de acadêmicos, a oferta de serviços educacionais no exterior envolvendo a mobilidade de experts em áreas de interesse estratégico, a exportação de programas e instalação de instituições ou campi no exterior; nos países periféricos ela se manifesta de forma diferente: observa-se a necessidade de definir criteriosa política de emissão de acadêmicos (principalmente professores-pesquisadores) para se formar nos grandes centros, objetivando investir no desenvolvimento de uma elite intelectual capaz de influir sobre o processo de modernização de alguns setores, apesar do elevado risco de perdê-la frente à reduzida capacidade de oferecer atrativas condições de trabalho e remuneração ao término da formação (VUILLETET, 2005). Além disso, a capacidade instalada (recursos materiais e humanos) de oferecer serviços educacionais no exterior, seja envolvendo programas, criação de campi ou instituições, é limitada quando estes países sequer respondem quantitativa e qualitativamente à demanda interna. Esta forma de inserção no sistema de educação mundial reforça o histórico desequilíbrio existente entre os países do Norte e do Sul, como será possível perceber.

Quando no contexto do capitalismo cognitivo o conhecimento (knowledge) ganha centralidade por ser reconhecido como a principal força produtiva (OECD, 2007), a hegemonia exercida pelos países que dispõem de sistema educacional consolidado (porque acessível e concatenado às exigências do período histórico) parece não causar estranhamento. Além de contribuir para a educação dos jovens, colabora para o desenvolvimento de competências que 
os capacitam a enfrentar os desafios contemporâneos e conquistar o poder de influir sobre o desenho do futuro e o destino de muitos. Consoantes a esta lógica, cada vez mais as instituições de educação superior em operação nos países centrais trabalham para a utilização privada do conhecimento (marchandisation des savoirs - VUILLETET, 2005, p. 5), ferindo a autonomia (einsamkeit) e a liberdade (freheit) acadêmicas - princípios basilares da universidade alemã, preconizados por Wilhelm von Humboldt (1997, p. 80). Nos termos de Brouillette e Fortin (2004, p. 5),

Depuis 20 ans, la recherche universitaire c'est graduellement commercialisée et même industrialisée. La compétition économique internationale eut por effet d'introduire dans l'espace commercial tout le domaine de la recherche et du développement des produits et des procédés. Les universités, comme centres traditionnels de la recherche, ont donc été interpellées par les entreprises nationales pour qu'elles répondent à cette compétition.

Mais do que nunca, a atração de estudantes internacionais passa a representar divisas resultantes da imposição de taxas de inscrição e anuidades, despesas que os estudantes (por meio de bolsas de estudo ou investimento proveniente das respectivas famílias) precisam arcar (transporte, habitação, alimentação, saúde, lazer etc.) durante o séjour de estudo; sem desconsiderar o potencial de promover o país de acolhimento (língua, cultura, interesses políticos e econômicos etc.) no país de origem, ao término da formação. A defesa de tais interesses, além de justificar a formulação de políticas de Estado comprometidas com a "caça aos estudantes solvíveis" (CHARLE et al., 2004, p. 968), valida decisões de liberar verbas para a criação e funcionamento de agências governamentais imbuídas da promoção do sistema de educação do país e respectivos atores (British Council (http://www.britishcouncil.org/), Fulbright Commission (http:// www.fulbright.co.uk/), Deutscher Akademischer Austausch Dienst (http:// www.daad.de/deutschland/), Agence CampusFrance (http://www.edufrance. fr/), Japan International Cooperation Agency (http://www.jica.go.jp/), Agencia Española de Cooperación Internacional para el Desarrollo (http://www.aecid. es/), Association des Universités et Collèges du Canada (http://www.aucc.ca/), International Development Programme Education Australia (http://www.idp. $\mathrm{com} /$ ) seriam exemplos do que se deseja ressaltar). Em tempo algum, os números relativos à mobilidade de acadêmicos internacionais foram contabilizados e divulgados com tanta freqüência e sistematização. ${ }^{1}$

1 Os dados divulgados em sítios oficiais impressiona - http://stats.uis.unesco.org/unesco/tableviewer/ 
Com a crescente valorização do conhecimento, Estado, empresas internacionalmente competitivas e algumas famílias passam a identificar e valorizar os centros acadêmicos que fomentam pesquisa e formam profissionais cosmopolitas (IANNI, 2005) - valiosos para o país, as empresas e com elevadas chances de sucesso profissional ${ }^{2}$. Assim, a concentração dos melhores ativos no campo científico e tecnológico apenas reforça a concentração já existente em outras esferas (militar e econômica, por exemplo). Neste contexto, os desequilíbrios regionais se alargam à medida que há flagrante descompasso entre os ativos conquistados nos países centrais e periféricos.

Considerando que os sistemas de educação dos países centrais nutrem interesse de acolher pessoas e, simultaneamente, os países periféricos necessitam enviar parte dos acadêmicos para estudar em universidades mundialmente notabilizadas, a educação internacional caminharia na direção de uma outra globalização, em que se ultrapassaria a estreiteza do pensamento único na busca da formação de verdadeira consciência universal? (SANTOS, 2006) Ao elaborar documento para a presidência da Assemblée Nationale da França, a deputada Aurélie Filippetti (2007, p. 17-19) estima que os países reconhecidos pela capacidade de atração e acolhimento de acadêmicos além de capitalizar recursos financeiros diretos e indiretos (sem penalizar os estudantes nacionais e o orçamento do Estado), contribui para: ampliar a rede mundial de influência cultural e política (a); selecionar os melhores cérebros (b); beneficiar-se de mão de obra qualificada (mesmo que por tempo determinado) (c); promover transferência de tecnologia (d); criar ambiente de aprendizagem de caráter multicultural (e); renovar a pesquisa e resistir à fuga de cérebros (f); além de enfrentar a imigração não-controlada (g). Então, como associar a internacionalização da educação a processos de integração, baseados na solidariedade e cooperação internacional, quando os recursos humanos e materiais provenientes dos países da periferia da economia mundo ajudam a financiar a educação dos países centrais? Tais condições contribuem para a emergência do que Boaventura de Sousa Santos (2002), António Teodoro (2003) e Roger Dale (2004) nomeiam de globalização hegemônica.

Em 2005, Knight (p. 26) classificou as razões que justificariam o investimento requerido pela internacionalização da educação em níveis macro (países) e

document.aspx?ReportId=143; http://www.pleiade.education.fr/portal/pleiade/depp; http://opendoors. iienetwork.org/; http://www.wissenschaft-weltoffen.de/; http://www.hesa.ac.uk/; http://www.hesa.ac.uk/ consulta realizada em outubro de 2008.

2 Resultados de pesquisa realizada pelo Institut der Deutschen Wirtschaft Köln (apud VUILLETET, 2005, p. 34) revela que uma empresa sobre três oferece melhores perspectivas de emprego e remuneração aos titulares de duplo diploma. 
meso (instituição de educação), considerando quatro categorias: socioculturais, políticas, econômicas e universitárias (Quadro 1). O conjunto das informações sugere que a visão da pesquisadora privilegia a perspectiva dos países que protagonizam a internacionalização ativa, e algumas questões ajudam a entender a assertiva: o acesso à internacionalização da educação (seja envolvendo a mobilidade de pessoas, circulação de programas ou instalação de instituições e campi fora do país de origem) tem ocorrido mundialmente? O processo de internacionalização em curso está orientado pelos mesmos propósitos? Tem alcançado os mesmos objetivos? Considerando as contribuições de Knight (2005) e Filippetti (2007), em quais países a internacionalização da educação influi sobre a construção de uma nação, a promoção de alianças estratégicas, o desenvolvimento sociocultural de um conjunto de países, ou representa notabilidade internacional, geração de renda, e melhoria da imagem de marca para as instituições envolvidas?

\begin{tabular}{|l|l|l|}
\hline Razões de ser & No âmbito dos PAÍSES & $\begin{array}{l}\text { No âmbito das INSTITUIÇÕES } \\
\text { de EDUCAÇÃo }\end{array}$ \\
\hline $\begin{array}{l}\text { De caráter } \\
\text { POLÍTICO }\end{array}$ & $\begin{array}{l}\text { Construção da nação } \\
\text { Estabelecimento de alianças } \\
\text { estratégicas }\end{array}$ & $\begin{array}{l}\text { Estabelecimento de alianças } \\
\text { estratégicas } \\
\text { Notabilidade internacional }\end{array}$ \\
\hline $\begin{array}{l}\text { De caráter } \\
\text { ECONÔMICO }\end{array}$ & $\begin{array}{l}\text { Estabelecimento de trocas } \\
\text { comerciais } \\
\text { Formação de renda } \\
\text { Valorização dos recursos } \\
\text { humanos }\end{array}$ & $\begin{array}{l}\text { Imagem de marca } \\
\text { Geração de renda }\end{array}$ \\
\hline $\begin{array}{l}\text { De caráter } \\
\text { UNIVERSITÁRIO }\end{array}$ & $\begin{array}{l}\text { Reforço da instituição de } \\
\text { educação }\end{array}$ & $\begin{array}{l}\text { Produção de conhecimento } \\
\text { Elevação da qualidade } \\
\text { Aperfeiçoamento dos professores e } \\
\text { dos estudantes }\end{array}$ \\
\hline $\begin{array}{l}\text { De caráter } \\
\text { SOCIOCULTURAL }\end{array}$ & $\begin{array}{l}\text { Desenvolvimento sociocultural } \\
\text { Compreensão mútua }\end{array}$ & \multicolumn{2}{|l|}{} \\
\hline
\end{tabular}

Quadro 1: As razões de ser na Internacionalização

Fonte: Adaptação de Jane Knight (2005. p. 26) "Modèle d'internationalisation ou comment faire face aux réalités et enjeux nouveaux". In: OCDE. L'enseignement supérieur en Amérique latine: la dimension internationale. Paris: Organization de Coopération et de Développement Économique.

A leitura do fenômeno proposta por Knight (2005) e Filippetti (2007) equivale aceitar que as motivações que justificariam a mobilidade internacional de acadêmicos seriam as mesmas. Mas não é isso que ocorre: ao reagrupar os resultados do estudo desenvolvido por Larsen e Vincent-Lancrin (2002), calcado no mapeamento das motivações que levam às migrações estudantis, é possível 
diferenciar aquelas típicas de acadêmicos oriundos de países com inserção ativa e passiva no sistema mundial de educação superior (Quadro 2). Ao classificar as motivações, identificadas pelos autores - socioculturais (4), acadêmicas (2), econômicas (6) e administrativas (4) -, percebe-se que enquanto as categorias de natureza econômica exercem maior importância entre os grupos formados de estudantes de países com inserção passiva no sistema mundial de educação (comparação entre os custos financeiros envolvidos na formação oferecida nos países de origem e de destino; possibilidade de trabalhar durante o séjour de estudo e obter algum recurso financeiro ou existência de oportunidades no mercado de trabalho e possibilidade de permanecer no país de destino após o término do curso), elas exercem pouca ou nenhuma importância entre os estudantes de países com inserção ativa. O texto de Ballatore e Blöss (Le sens caché de la mobilité des étudiants Erasmus, 2008) ilustra a questão ao desenvolver uma análise comparativa da mobilidade internacional entre estudantes italianos, franceses e ingleses.

Quando os fatores econômicos prevalecem, observa-se expressiva mobilidade na direção de países em que a educação permanece predominantemente pública (França, Finlândia, Alemanha, Cuba etc.) ou países que oferecem infra-estrutura de acolhimento e ainda permite ao estudante trabalhar 20 horas semanais (EUA, Reino Unido, Austrália, Nova Zelândia etc.). Observa-se ainda a influência exercida pelos critérios de contratação/promoção adotados por empresas multinacionais: pleno domínio da língua, capacidade de compreender a cultura do país de origem da organização, e facilidade de trabalhar em ambientes multiculturais são fatores crescentemente valorizados - nas palavras de Vuilletet (2005, p. 36), "les entreprises jouent de plus en plus un rôle actif en faveur de la mobilité internationale des étudiants". Quando prevalecem critérios de natureza acadêmica, os centros que conquistaram notório prestígio internacional são os mais procurados por se revelarem qualitativamente superior aos existentes no país com forte taxa de emissão de estudantes internacionais (Quadro 2).

Aspectos administrativos podem facilitar ou dificultar o deslocamento e permanência dos estudantes no país de acolhimento - as dificuldades de obtenção de visto ou de equivalência de diplomas são crescentes em países que reconhecem a mobilidade de estudantes (particularmente aqueles oriundos de países periféricos) como uma espécie de "trabalhadores imigrados disfarçados" (CHARLE et al., 2004, p. 967). Razão pela qual, praticamente todos os países passaram a exigir seguro de saúde, passagem aérea (ida/volta), endereço fixo no país de acolhimento, comprovação de renda, além da capacidade de o acadêmico 


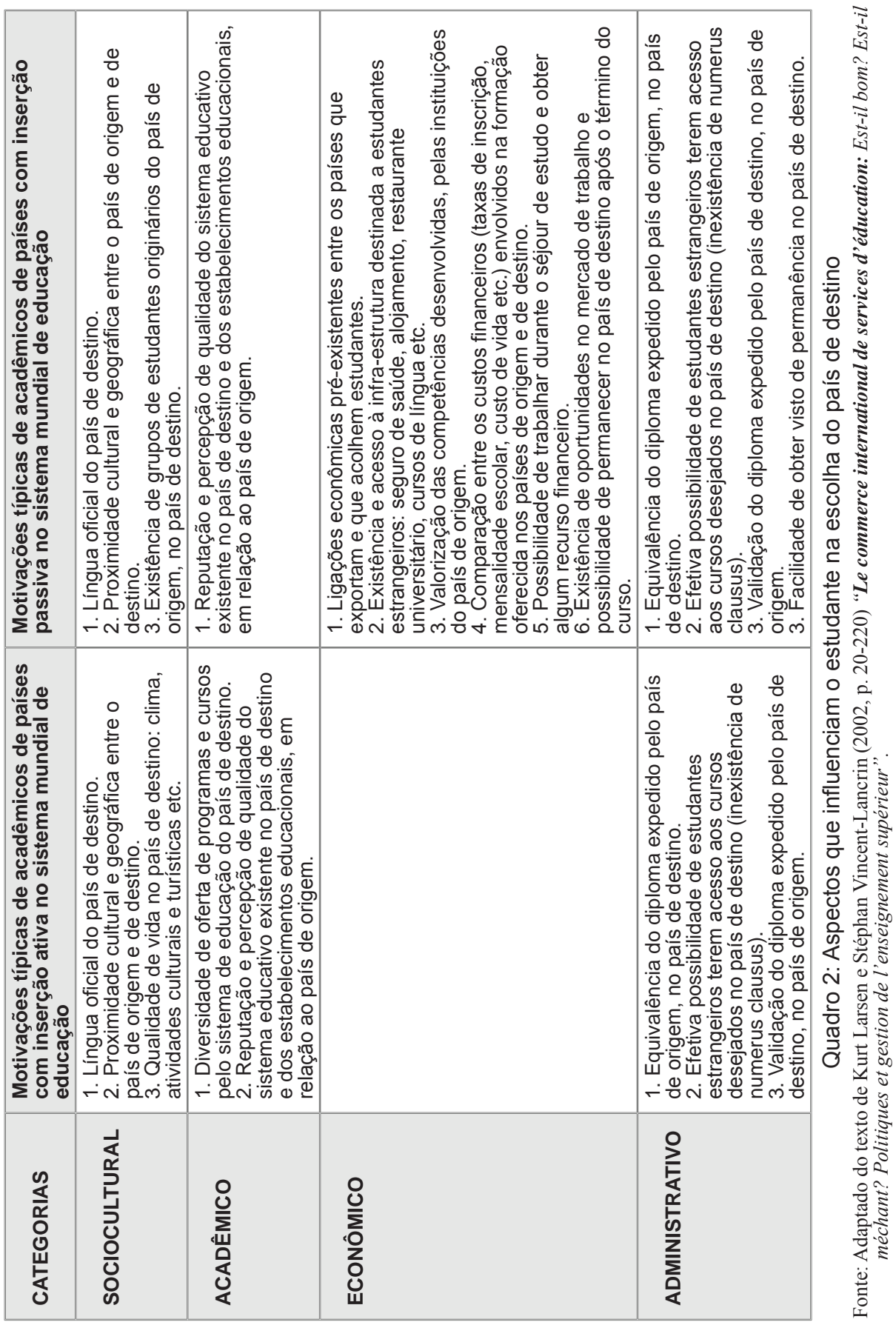


se manter no país durante o séjour de estudo. Neste contexto, é difícil concordar que algumas razões de cunho sociocultural, levantadas por Knight (2005, p. 26), - desenvolvimento sociocultural ou compreensão mútua - tenham, neste contexto, alguma relevância. Fica evidente que a educação internacional desde sempre é um affaire para poucos (CHARLE et al., 2004, p. 967; RIDDERSYMOENS, 2002, p. 416). Ianni (2005, p. 154) chama atenção para o fato de a intolerância frente ao outro não ter sido alterada com a crescente valorização da educação internacional,

Os próprios europeus - brancos, civilizados, portadores dos emblemas da democracia, cidadania e humanismo - surpreendem-se com as presenças desajeitadas, diferentes, incômodas de imigrantes de todo o tipo. [Entretanto,] precisam de sua força de trabalho, do excedente que produzem, da sua capacidade de realizar tarefas inferiores, desprezíveis, mas não toleram a sua presença social, cultural e política.

Contudo, vale lembrar que recorrentemente os aspectos socioculturais levantados por Larsen e Vincent-Lancrin (2002) são explorados pelos países que adotam agressiva política de captação de estudantes internacionais - em que Estado, embaixadas, consulados, universidades, câmaras de comércio, indústrias de conteúdo (software, recursos digitais, editoras), provedores de e-learning, indústria de serviços (exames, acreditação, consultoria especializada), indústria do turismo etc. somam esforços - de modo a ressaltar os diferenciais competitivos que justificam o investimento dos estudantes solvíveis (CHARLE et al., 2004, p. 968). Nesta direção, a Austrália tem sido destino preferido de jovens que desejam aprender inglês, obter algum recurso trabalhando meio período, sem deixar de aproveitar as belezas do país, com investimentos incomparáveis aos requeridos por programa similar nos EUA ou Reino Unido. A França, por sua vez, chama atenção para o patrimônio cultural encontrado no país, a notabilidade das grandes écoles, a proximidade com pólos culturais, políticos e econômicos europeus (Luxemburgo, Bruxelas, Colônia, Genebra, Lousane, Milão, Barcelona etc.), e para uma espécie de democracia baseada na tolerância face ao diferente - em 2005 a França recebeu 50.637 estudantes do Marrocos, 25.517 da Argélia, e 15.488 da Tunísia (UNESCO, 2007), por exemplo.

\section{A mobilidade estudantil - panorama mundial: situando a internacionalização ativa}

Devido aos custos e complexidade intrínsecos às pesquisas de âmbito mundial, a responsabilidade por sua realização tem recaído sobre organismos 
multilaterais que conquistaram alcance e credibilidade, indispensáveis à execução da coleta de dados. Cientes disso, far-se-á uso de relatórios divulgados pela UNESCO $(2003,2004,2005,2006,2007)$ e OCDE (2006). A consulta aos documentos cujo conteúdo reproduz séries históricas referentes aos números que revelam a mobilidade internacional de estudantes sinaliza pronunciada curva de crescimento. Entretanto, a expressividade deste crescimento tem sido maior de 1995 em diante: entre 1995 e 2005 o número de estudantes mais que dobrou; entre 2000 e 2005 o número cresceu cerca de 800 milhões (Quadro 3).

\begin{tabular}{|l|l|l|l|l|l|l|l|}
\hline PERÍODO & 1975 & 1980 & 1985 & 1990 & 1995 & 2000 & 2005 \\
\hline NÚMERO ESTUDANTES & 600 & 800 & 900 & 1200 & 1300 & 1900 & 2700 \\
\hline PERÍODO & - & $1975 / 80$ & $1980 / 85$ & $1985 / 90$ & $1990 / 95$ & $1995 / 00$ & $2000 / 05$ \\
\hline TAXA CRESCIMENTO (\%) & - & 33,3 & 12,5 & 33,3 & 8,3 & 46,1 & 42,1 \\
\hline
\end{tabular}

Quadro 3: Evolução mundial do número de estudantes estrangeiros no ensino superior (em milhares) 1975-2004

Fonte: OCDE. Education at a glance (2006).

Cruzar o destino com a origem dos estudantes internacionais contribuirá para o raciocínio em construção. A hegemonia exercida pelas instituições norteamericanas e européias (Europa Ocidental) está estampada nos números: as instituições educacionais localizadas nas duas macro-regiões foram responsáveis pelo acolhimento de 1.851.018 estudantes, em 2005. Juntas, elas representam o principal destino dos estudantes da Ásia de Leste e Pacífico (426.223), América do Norte e Europa Ocidental (417.400), Europa Central e Oriental (230.409), Ásia do Sul e Oeste (156.079), África Sub-Saariana (133.916), Estados Árabes (132.864), América Latina e Caribe (129.485) (Quadro 7). Mas enquanto as duas regiões (América do Norte e Europa Ocidental) atraem expressivo contingente de estudantes internacionais (1.851.018), quatro - Ásia do Sul e Oeste (10.303), Ásia Central (33.958), América Latina e Caribe (36.536) e África Sub-Saariana (59.801) - acolhem menos de 10\% dos estudantes internacionais (140.328) (Quadro 4). Apesar de não ser o foco deste artigo, é impossível desconsiderar o impacto econômico decorrente da mobilidade acadêmica. ${ }^{3}$ Então, caberia questionar: quais são os países que efetivamente investem no

3 No meio da década de 90, a OCDE estimava que o comércio internacional de estudantes correspondia a “30 milliards de dollars US”. (BROUILLETTE; FORTIN, 2004, p. 26) 
estabelecimento de alianças estratégicas, trocas comerciais, geração de renda, e formação de imagem de marca? Quem envia (outbound) e quem acolhe (inbound) estudantes internacionais? Quem se capitaliza com a comercialização de serviços educacionais?

\begin{tabular}{|l|r|r|}
\hline \multicolumn{1}{|c|}{ REGIÕES } & $\mathbf{2 0 0 4}$ & \multicolumn{2}{c|}{$\mathbf{2 0 0 5}$} \\
\hline ESTADOS ÁRABES & 61983 & 67440 \\
\hline EUROPA CENTRAL e ORIENTAL & 168015 & 209356 \\
\hline ÁSIA CENTRAL & 33958 & 40993 \\
\hline ÁSIA de LESTE e PACÍFICO & 379919 & 452853 \\
\hline AMÉRICA LATINA e CARIBE & 36536 & 33987 \\
\hline AMÉRICA do NORTE/EUROPA OCIDENTAL & $\mathbf{1 7 0 4 7 3 5}$ & $\mathbf{1 8 5 1 0 1 8}$ \\
\hline ÁSIA do SUL e OESTE & 10303 & 10658 \\
\hline ÁFRICA SUBSARIANA & 59801 & 62175 \\
\hline MUNDO & $\mathbf{2 4 5 5 2 5 0}$ & $\mathbf{2 7 2 8 4 8 0}$ \\
\hline
\end{tabular}

Quadro 4: Distribuição dos estudantes internacionais - média regional de recepção (2004-2005)

Fonte: Recueil de Données Mondiales sur l’Éducation. Institut de Statistique. UNESCO, 2006; 2007.

Conhecer o país de destino escolhido pelo contingente de estudantes internacionais (2.728.480) possivelmente ajude a avaliar até que ponto as razões de ser da internacionalização da educação superior, apontadas por Knight (2005, p. 26), convergem entre os países responsáveis pela emissão e recepção. Os dados do Quadro 5 revelam que apesar do crescimento exponencial da mobilidade estudantil, poucos países são capazes de atrair o interesse dos estudantes internacionais.

\begin{tabular}{|l|r|r|r|r|r||}
\hline \multicolumn{1}{|c|}{ PAÍSES } & \multicolumn{1}{c|}{$\mathbf{2 0 0 1}$} & \multicolumn{1}{c|}{$\mathbf{2 0 0 2}$} & \multicolumn{1}{c|}{$\mathbf{2 0 0 3}$} & \multicolumn{1}{c|}{$\mathbf{2 0 0 4}$} & \multicolumn{1}{c|}{$\mathbf{2 0 0 5}$} \\
\hline ESTADOS UNIDOS & 475169 & 582996 & 582996 & 572509 & 590128 \\
\hline REINO UNIDO & 225722 & 225722 & 227273 & 300056 & 318399 \\
\hline ALEMANHA & 199132 & 219039 & 240619 & 260314 & 259797 \\
\hline FRANÇA & 147402 & 147402 & 221567 & 237587 & 236518 \\
\hline AUSTRÁLIA & 105764 & 120987 & 179619 & 166954 & 207264 \\
\hline CANADÁ & 40033 & 40033 & 40033 & 40033 & 132982 \\
\hline JAPÃO & 63637 & 74892 & 74892 & 117903 & 125917 \\
\hline
\end{tabular}

Quadro 5: Principais países receptores de estudantes (2001-2005)

Fonte: Recueil de Données Mondiales sur l’Éducation. Institut de Statistique. UNESCO, 2003, 2004, 2005, 2006, 2007. 
A presença de estudantes internacionais por país de acolhimento parece inversamente proporcional à matrícula: enquanto nos EUA a porcentagem de estudante internacional não ultrapassa 3,3\%; no Reino Unido ela corresponde a 14,1\%; na França, 11,7\%; na Alemanha, 12,5\%; e na Austrália ela atinge 23,3\% (CAMPUSFRANCE, 2008). Estes números desconsideram os dados relativos ao ensino à distância (EAD), apesar da crescente popularização desta modalidade de ensino e de diversos países adotarem medidas restritivas à imigração (EUA, Inglaterra, Espanha e França são exemplos disso).

Até o início da década de 90 a matrícula de estudantes internacionais se concentrava em programas de pós-graduação stricto sensu, de 1995 em diante, este quadro vem se modificando e atualmente a preocupação de investir em formação internacional é cada vez mais antecipada entre representantes de estratos socioeconômicos privilegiados, sejam eles subsidiados pelo Estado (programa Erasmus, na Europa) ou não: na França a procura por cursos equivalentes à graduação corresponde a metade da matrícula internacional (49,9\%); na Austrália ela chega a 56\%; e na Alemanha, a 69,5\%. A internacionalização tem reforçado o processo de elitização da educação superior porque apesar de os diplomas expedidos no exterior serem socialmente valorizados, a educação internacional ainda permanece uma experiência acessível a poucos em razão dos investimentos requeridos (Quadro 6).

A mobilidade custa caro, e imaginar que um dia um programa europeu de dimensão faraônica permitirá que qualquer estudante possa ficar no exterior por um bom tempo (pelo menos uma vez durante a sua escolaridade), quando a prioridade alardeada é a limitação dos financiamentos públicos, parece não passar de carta de intenção. A realidade é muito mais prosaica: por motivos de custos, a mobilidade em boas condições será reservada a quem puder pagar por ela, e a quem tiver sido selecionado como fazendo parte da elite merecedora, duas categorias que costumam se recobrir e que na França, por sinal, convergem para a mesma figura do aluno das carreiras (ou áreas do conhecimento) seletivas. (CHARLE et al., 2004, p. 968)

\begin{tabular}{|l|r|r|r|r|r||}
\hline \multicolumn{1}{|c|}{ Nível de Formação } & Estados Unidos & Reino Unido & França & Alemanha & Austrália \\
\hline GRADUAÇÃO & $29,2 \%$ & $47 \%$ & $49,9 \%$ & $69,5 \%$ & $56 \%$ \\
\hline MESTRADO & $21 \%$ & - & $37,7 \%$ & $15,7 \%$ & - \\
\hline DOUTORADO & $19 \%$ & - & $12,4 \%$ & $8,4 \%$ & - \\
\hline MESTRADO+DOUTORADO & $40 \%$ & $52,4 \%$ & $50,1 \%$ & $24,1 \%$ & $44 \%$ \\
\hline \hline
\end{tabular}

Quadro 6: Matrícula internacional por nível de formação (2006-2007)

Fonte: Agence CampusFrance. Les étudiants internationaux: chiffres clés. 2008. 
Não seria um despropósito afirmar a influência exercida por tais sistemas de educação superior sobre a organização e desenvolvimento do sistema mundial de educação. Isto é particularmente perceptível entre os países que integraram o referido sistema pela lógica da internacionalização passiva, à medida que as respectivas lideranças acadêmicas e políticas são influenciadas pelo modelo de educação que se revela hegemônico e tendem a reproduzir ou adaptá-lo às realidades regionais - afinal ele vem sendo associado à produção de conhecimento, à elevação da qualidade do ensino e da pesquisa, à formação de gestores e professores e ainda ao aperfeiçoamento dos estudantes! (Quadro 1). Estes objetivos não seriam intrínsecos à internacionalização ativa?

Por fim, chama-se atenção para a representatividade dos estudantes internacionais por macro-região (Quadro 7) porque aquelas que ainda não conseguiram consolidar os respectivos sistemas de educação superior são justamente as mais sub-representadas: a região responsável pelo maior contingente de estudante internacional é Ásia de Leste e Pacífico (766.351), em seguida vem a América do Norte e Europa Ocidental (472.607), a Europa Central e Oriental (314.887), a Ásia do Sul e Oeste (214.744), a África SubSaariana (192.877), os Estados Árabes (180.731) e por último a América Latina e Caribe (157.789).

\section{A mobilidade estudantil - panorama mundial: situando a internacionalização passiva}

Os números relativos à mobilidade estudantil revelam que a emissão é geograficamente mais dispersa do que a recepção. Considerando os países que enviaram mais de cinqüenta mil estudantes em 2005 verifica-se que: apenas oito são responsáveis por aproximadamente um terço da matrícula internacional: 913.138 de um total de 2.728.480 estudantes (a); quatro estão localizados na Ásia (China, Índia, Coréia e Japão), e juntos são responsáveis por mais de 20\% dos estudantes internacionais: 696.649 (b); apenas dois países europeus estão representados no grupo (Alemanha e França): dos 115.436 enviados, 93.370 permaneceram em instituições e países europeus (Reino Unido, Bélgica, Suíça, Países Baixos, Alemanha e Áustria) revelando a importância assumida pelo programa Erasmus (c). (Quadro 8). 


\begin{tabular}{|c|c|c|c|c|c|c|c|c|c|c|}
\hline $\bar{z}$ & $\begin{array}{l}\stackrel{M}{\tilde{O}} \\
\stackrel{\text { N }}{N}\end{array}$ & $\begin{array}{l}\text { L } \\
\stackrel{+}{+} \\
\text { N่ } \\
\text { గn }\end{array}$ & : & 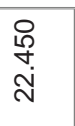 & $\underset{\text { N̦ }}{\stackrel{N}{N}}$ & 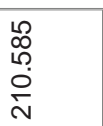 & 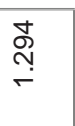 & $\begin{array}{l}\infty \\
\infty \\
\stackrel{D}{N} \\
\stackrel{N}{N}\end{array}$ & 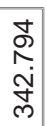 & \\
\hline 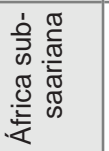 & 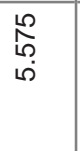 & $\begin{array}{l}\underset{H}{\sim} \\
\text { ㄱ }\end{array}$ & $\stackrel{\sim}{N}$ & $\begin{array}{l}\stackrel{\text { D }}{\infty} \\
\infty \\
\sigma\end{array}$ & 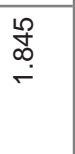 & $\begin{array}{l}\stackrel{0}{ } \\
\text { ğ } \\
\text { लై }\end{array}$ & \begin{tabular}{l}
0 \\
\multirow{6}{*}{} \\
$\stackrel{-}{-}$
\end{tabular} & $\begin{array}{l}\mathbb{N} \\
\text { } \\
\infty \\
\infty\end{array}$ & 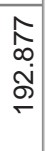 & \\
\hline 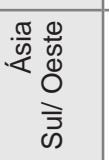 & $\begin{array}{l}\infty \\
\stackrel{-}{\rightarrow} \\
\rightarrow\end{array}$ & 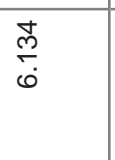 & $\begin{array}{c}-\vec{D} \\
\stackrel{m}{0} \\
m\end{array}$ & $\begin{array}{l}\underset{N}{\mathbb{N}} \\
\underset{\forall}{\dot{J}}\end{array}$ & 8 & 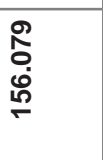 & $\underset{\sim}{\stackrel{\sim}{\sim}}$ & $\stackrel{\bullet}{\sim}$ & 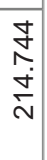 & 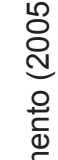 \\
\hline 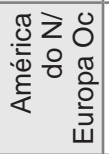 & ָָ & 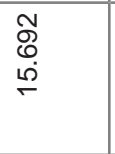 & $\widetilde{N}$ & $\begin{array}{l}\underset{\widetilde{N}}{\tilde{C}} \\
\stackrel{m}{m}\end{array}$ & $\begin{array}{l}\underset{\sim}{\sim} \\
\stackrel{\sim}{\sim}\end{array}$ & 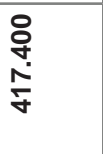 & ભ & ஜ্ & 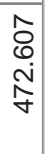 & 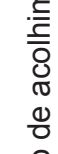 \\
\hline 党 & $\underset{\forall}{\stackrel{Y}{\forall}}$ & ঙ্লি & $\nabla$ & $\begin{array}{l}\underset{+}{J} \\
\stackrel{+}{+}\end{array}$ & 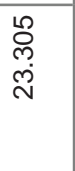 & $\begin{array}{l}\text { L̊ } \\
\text { \& } \\
\text { ホ̀ }\end{array}$ & $\mathbb{N}$ & $\checkmark$ & 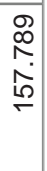 & 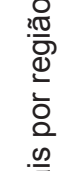 \\
\hline 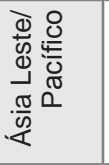 & 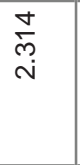 & $\begin{array}{l}\stackrel{\oplus}{N} \\
\text { ه్ }\end{array}$ & $\begin{array}{l}-\overrightarrow{0} \\
\infty \\
-i \\
-i\end{array}$ & 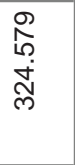 & 암 & 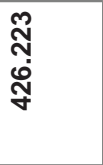 & $\begin{array}{l}0 \\
\stackrel{0}{0} \\
\Theta \\
-\end{array}$ & পু & $\begin{array}{l}-1 \\
\text { ñ } \\
0 \\
0 \\
0\end{array}$ & 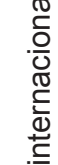 \\
\hline$\frac{\frac{\pi}{\omega}}{\frac{\pi}{2}}$ & 㤐 & $\begin{array}{l}\text { mo } \\
0 \\
0 \\
0 \\
0\end{array}$ & 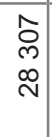 & $\begin{array}{l}\text { No } \\
\text { o } \\
- \\
-i\end{array}$ & $\underset{\gamma}{ }$ & $\begin{array}{l}\hat{\infty} \\
0 \\
\dot{J} \\
\overrightarrow{-}\end{array}$ & 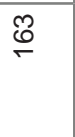 & 1 & $\begin{array}{l}\widetilde{N} \\
\infty \\
\infty \\
\infty\end{array}$ & $\begin{array}{l}\mathscr{D} \\
\stackrel{\mathbb{C}}{\frac{\pi}{\pi}} \\
\frac{0}{0}\end{array}$ \\
\hline 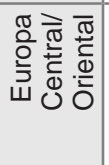 & 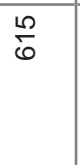 & 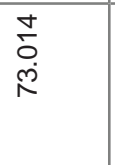 & $\begin{array}{l}n \\
\stackrel{n}{N} \\
0\end{array}$ & $\begin{array}{l}\stackrel{9}{+} \\
\stackrel{+}{+}\end{array}$ & $\begin{array}{l}\infty \\
1 \\
1\end{array}$ & 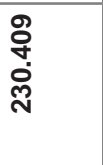 & $\hat{\exists}$ & 유 & $\begin{array}{l}\hat{\infty} \\
\infty \\
\dot{\sim} \\
\dot{m}\end{array}$ & 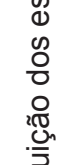 \\
\hline 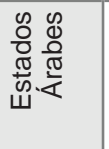 & $\begin{array}{l}\hat{\sim} \\
\text { N } \\
\text { N }\end{array}$ & 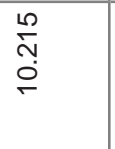 & $\begin{array}{l}\mathscr{g} \\
\infty\end{array}$ & 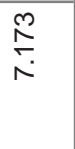 & $\underset{\neg}{\stackrel{\mathscr{P}}{+}}$ & 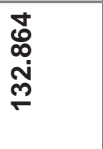 & $\begin{array}{l}\stackrel{L}{N} \\
\text { ه్ }\end{array}$ & น & $\begin{array}{l}-1 \\
\stackrel{-1}{\sim} \\
\dot{0} \\
\infty \\
-1\end{array}$ & 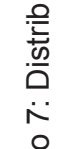 \\
\hline 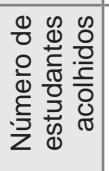 & 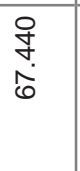 & $\begin{array}{l}0 \\
\stackrel{0}{0} \\
\ddot{D} \\
\stackrel{N}{N}\end{array}$ & $\begin{array}{l}m \\
\stackrel{n}{\sigma} \\
\stackrel{+}{+}\end{array}$ & 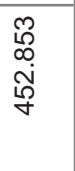 & $\begin{array}{l}\hat{\infty} \\
o \\
\stackrel{m}{m}\end{array}$ & 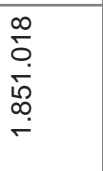 & 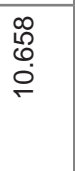 & 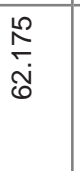 & $\begin{array}{l}\stackrel{0}{\infty} \\
\stackrel{\infty}{+} \\
\infty \\
\stackrel{N}{N} \\
\text { iv }\end{array}$ & 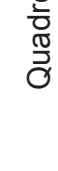 \\
\hline 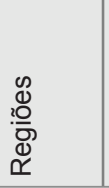 & 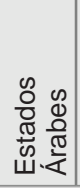 & 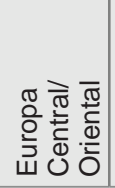 & 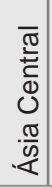 & 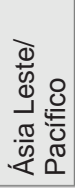 & 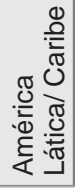 & 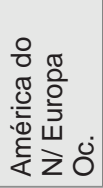 & 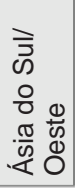 & 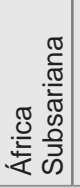 & $\frac{\stackrel{0}{0}}{\frac{D}{2}}$ & \\
\hline
\end{tabular}




\begin{tabular}{|c|c|c|c|c|c|c|c|c|}
\hline 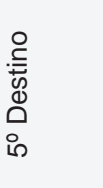 & 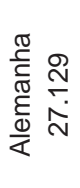 & 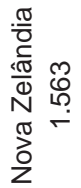 & 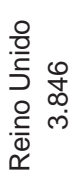 & 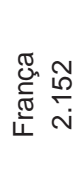 & 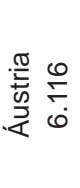 & 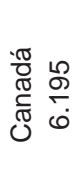 & 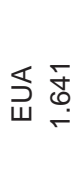 & 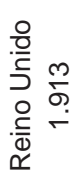 \\
\hline 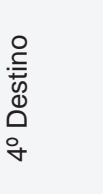 & 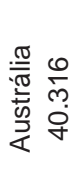 & 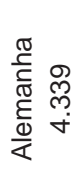 & 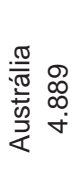 & 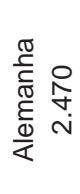 & 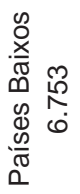 & 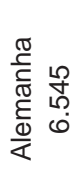 & 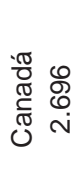 & 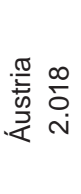 \\
\hline 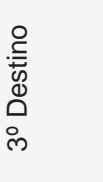 & 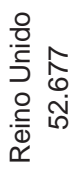 & 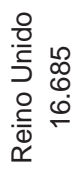 & 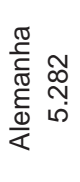 & 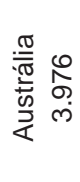 & 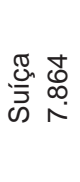 & 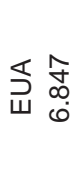 & 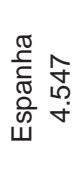 & 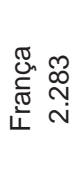 \\
\hline 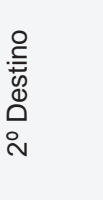 & 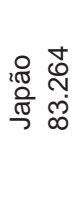 & 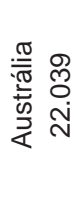 & 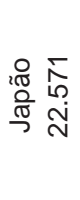 & 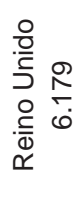 & 离 & 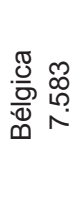 & 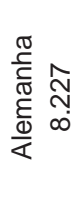 & 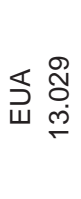 \\
\hline 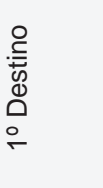 & 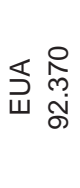 & 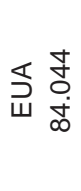 & 离 & 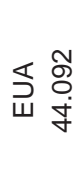 & 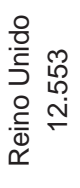 & 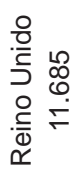 & 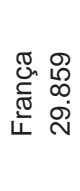 & 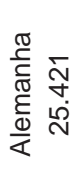 \\
\hline 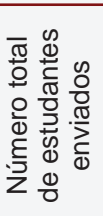 & 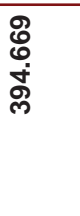 & 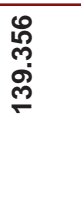 & 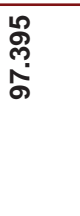 & 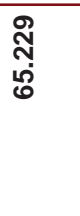 & $\begin{array}{l}\text { : } \\
\text { ஸి } \\
\text { రై }\end{array}$ & 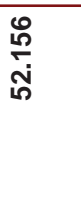 & $\begin{array}{l}\hat{\dddot{g}} \\
\text { டें }\end{array}$ & $\begin{array}{l}0 \\
7 \\
7 \\
8 \\
\text { டे }\end{array}$ \\
\hline$\frac{\omega}{w}$ & : & $\begin{array}{l}\stackrel{\underline{\sigma}}{0} \\
. \underline{\underline{C}}\end{array}$ & 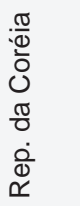 & 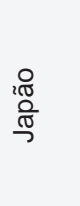 & 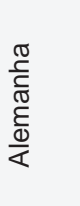 & 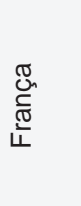 & 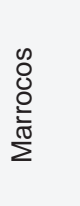 & 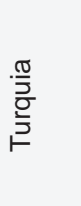 \\
\hline
\end{tabular}


O que explicaria a expressividade da matrícula internacional de estudantes chineses, indianos e coreanos (631.420 estudantes em 2005)? A China, Índia e Coréia se integram à economia mundo como países semi-periféricos, têm em comum acelerado processo de crescimento econômico, nem sempre acompanhado pela consolidação quantitativa e qualitativa do sistema de educação superior nacional (na Índia, por exemplo, apenas 7\% dos jovens entre 18 e 24 anos ingressam no ensino superior). Com isso, neste momento, a expertise alcançada pelos países desenvolvidos é fundamental para estes países. Determinados a ultrapassar esta limitação de forma mais rápida, governos e famílias investem na formação internacional dos jovens em áreas estratégicas para o crescimento do país e a empregabilidade.

As estatísticas e a literatura internacional sobre a pós-graduação registram o intenso fluxo de estudantes de países recém-industrializados para países cientificamente centrais. Nos Estados Unidos da América, por exemplo, cerca de um terço dos títulos de doutor são outorgados para estudantes estrangeiros. Nas Engenharias, essa proporção é mais de $50 \%$ dos diplomas concedidos na área, a maioria destes estudantes é proveniente da China, Índia e Coréia do Sul e Taiwan. Dados desse tipo sugeririam que a formação no exterior teria características que não seriam encontradas na titulação em países nos quais a maioria da atividade científica e tecnológica não poderia ser considerada inserida no mainstream da C\&T. (VELHO apud VELLOSO, 2006, p. 197)

Para que não pairem dúvidas acerca do volume de investimento requerido pelos programas de emissão de estudantes, chama-se atenção para a ausência de regiões e países mais carentes entre aqueles que estão mais bem representados na estatística da mobilidade estudantil passiva. Esta evidência aponta que o atual modelo de internacionalização favorece aqueles países que podem pagar por ele ou que recebem pelo serviço prestado.

Qual seria o destino preferido pelos estudantes internacionais? Enquanto a preferência dos asiáticos recai sobre as instituições estadunidenses; o Reino Unido é o país preferido pelos europeus (ou as universidades do Reino Unido preferem estudantes europeus?). As instituições européias, por sua vez, são preferidas pelos estudantes do Norte da África (Argélia, Marrocos e Tunísia). Em quais termos explicar tais rotas? A valorização do conhecimento, combinada ao encolhimento dos investimentos públicos em educação têm levado as universidades públicas diversificarem suas fontes de recursos financeiros, com a intensificação da comercialização de serviços educacionais. Desta forma, contribuem para o fortalecimento de ambiente favorável à privatização de um 
setor em crescente processo de desregulamentação - condições que estimulam a comercialização internacional de serviços educacionais. Prova disto é que o deslocamento de estudantes internacionais é mais expressivo entre países que instalaram sistemas de educação superior predominantemente privados (BROUILLETTE; FORTIN, 2004, p. 27-28). Entre os países europeus - Espanha, França, Alemanha, Reino Unido, Itália, por exemplo - a mobilidade acadêmica é estimulada como forma de integração cultural, social, política e econômica. Após 20 anos de existência, os números associados ao programa Erasmus revelam o tamanho do esforço por uma Europa política e economicamente forte. ${ }^{4}$

De que modo a mobilidade estudantil ocorre nos países da América latina? A inserção do continente ao sistema mundial de educação superior ocorre de forma predominantemente passiva ou ativa?

\section{A mobilidade estudantil - situação latino-americana}

Apesar de a América Latina e Caribe estarem em sintonia com a média mundial no que tange ao percentual de investimentos em Educação $\left(4,4 \%\right.$ do PIB) ${ }^{5}$ e a região abrigar nove universidades bem pontuadas na classificação internacional (Quadro 9), ${ }^{6}$ a sua capacidade de atração de estudantes internacionais é a mais baixa entre as diversas macro-regiões do globo: corresponde a única região que apresentou redução do efetivo de estudantes internacionais entre 2004/2005 (de 36.536 para 33.987).

Por mais que alguns países tenham investido na formação de universidades ainda no período colonial - Colômbia (1805), Argentinas (1821), Peru (1824), Bolívia (1830), Uruguai (1833), Chile (1842), Venezuela (1852) etc. (ROSSATO, 1998, p. 191-192) -; que as barreiras culturais e lingüísticas sejam modestas, se comparadas às enfrentadas pelos países da Comunidade Européia, por exemplo; que na maioria dos países, o acesso à educação superior se mantenha

4 “Alors que le programme Erasmus fête ses 20 ans d'existence, les chiffres de l'année 2005-2006 viennent d'être publiés. [...] Erasmus continue sa progression ; ce sont 155453 étudiants qui ont participé à un échange dans le cadre du programme, soit une augmentation de 7,3\% par rapport à l'année précédente. Ce chiffre reste assez proche des augmentations précédentes : 6,2\% en 2004-2005 et 9,4\% en 2003-2004. Le nombre d'enseignant participant est aussi en hausse de 12,4\% avec plus de 23400 participants. Disponível em: < http://www.etudiants-erasmus.com/2007/04/29/171-chiffres-erasmus-2006-2007>. Acesso em: out. 2008. 5 Estados Árabes $=4,9 \%$ do PIB; Europa Central e Oriental =4,2\%; Ásia Central = 2,8\%; Ásia de Leste e Pacífico = 2,8\%; América Latina e Caribe = 4,4\%; América do N. e Europa Oc. = 5,6\%; Ásia do Sul e Oeste $=3,6 \%$; África Sub-Saariana $=4,5 \%$ e Média mundial =4,4\% (UNESCO, 2007).

6 Há cinco anos (2003-2007), o Instituto de Ensino Superior da Shanghai Jiao Tong University elabora classificação mundial das universidades (Academic Ranking of World Universities). Classifica as 500 instituições mais bem pontuadas, levando em conta indicadores mundialmente comparáveis acerca da performance acadêmica. AAmérica Latina revela-se uma das regiões mais sub-representadas no referido ranking-apenas quatro países estão incluídos: Argentina (1), Brasil (5), Chile (2) e México (1). 


\begin{tabular}{|l|c|c|c|c|c|}
\hline \multicolumn{1}{|c|}{ Universidades / Países } & $1-99$ & $102-202$ & $203-304$ & $305-400$ & $401-500$ \\
\hline $\begin{array}{l}\text { Universidade de São Paulo } \\
\text { (BRASIL) }\end{array}$ & & $128^{\circ}$ & & & \\
\hline $\begin{array}{l}\text { Universidad de Buenos Aires } \\
\text { (ARGENTINA) }\end{array}$ & & X & & & \\
\hline $\begin{array}{l}\text { Universidad Nacional Autônoma } \\
\text { de México (MÉXICO) }\end{array}$ & & X & & & \\
\hline $\begin{array}{l}\text { Universidade Estadual de } \\
\text { Campinas (BRASIL) }\end{array}$ & & & $304^{\circ}$ & & \\
\hline $\begin{array}{l}\text { Universidade Federal do } \\
\text { Rio de Janeiro (BRASIL) }\end{array}$ & & & & $338^{\circ}$ & \\
\hline $\begin{array}{l}\text { Pontifícia Universidad Católica } \\
\text { (CHILE) }\end{array}$ & & & & & X \\
\hline Universidad de Chile (CHILE) & & & & $449^{\circ}$ \\
\hline $\begin{array}{l}\text { Universidade Estadual Paulista } \\
\text { (BRASIL) }\end{array}$ & & & & & $453^{\circ}$ \\
\hline $\begin{array}{l}\text { Universidade Federal de Minas } \\
\text { Gerais (BRASIL) }\end{array}$ & & & & \\
\hline
\end{tabular}

Quadro 9: Classificação das universidades latino-americanas no Academic Ranking of World Universities (2007)

Fonte: Disponível em: < http://ed.sjtu.edu.cn/rank/2007/ARWU2007_top100.htm>. Acesso em: 3 set. 2008.

limitado (Quadro 10), a variação da matrícula internacional revela que o sistema de educação superior ainda não alcançou maturidade e que os países ainda não dispõem de política capaz de estimular a internacionalização ativa. Governos e instituições dos países da região parecem mais desafiados a criar condições de acesso à educação, à população autóctone. Além disso, historicamente, as iniciativas ligadas à internacionalização da educação são predominantemente estabelecidas com os países hegemônicos e tradicionalmente associadas à emergência/amadurecimento da pós-graduação stricto sensu.

\begin{tabular}{|c|c|}
\hline $\begin{array}{l}\% \text { de Estudantes de } 18- \\
24 \text { no Ensino Superior }\end{array}$ & EXEMPLOS DE PAÍSES \\
\hline $14 \%$ a $33 \%$ & $\begin{array}{l}\text { África do Sul, Arábia Saudita, Argélia, Brasil, Colômbia, Costa Rica, } \\
\text { El Salvador, Eslováquia, Filipinas, Honduras, Jamaica, Jordânia, } \\
\text { Malásia, Mali, Mandagascá, México, Moldávia, Mongólia, Peru, } \\
\text { República Checa, Venezuela, Iran etc. }\end{array}$ \\
\hline $34 \%$ a $50 \%$ & $\begin{array}{l}\text { Argentina, Bolívia, Bulgária, Chile, Cuba, Egito, Hungria, Líbano, } \\
\text { Líbia, Panamá, Portugal etc. }\end{array}$ \\
\hline $51 \%$ a $74 \%$ & $\begin{array}{l}\text { Alemanha, Austrália, Áustria, Bélgica, Bielorússia, Canadá, Dinamar- } \\
\text { ca, Eslovênia, Espanha, Estônia, França, Holanda, Israel, Irlanda, } \\
\text { Israel, Itália, Japão, Lituânia, Nova Zelândia, Polônia, Reino Unido, } \\
\text { Rússia, Ucrânia etc. }\end{array}$ \\
\hline Mais de $75 \%$ & $\begin{array}{l}\text { Coréia do Sul, Dinamarca, EUA, Finlândia, Holanda, Suécia, Suíça } \\
\text { etc. }\end{array}$ \\
\hline
\end{tabular}

Quadro 10: Percentual de estudantes de 18-24 anos no ensino superior (2005) Fonte: Recueil de Données Mondiales sur l’Éducation. Institut de Statistique. UNESCO, 2007. 
Considerando a série histórica da UNESCO (2003, 2004, 2005, 2006, 2007), o Chile é único país que está representado em todos os períodos do levantamento. Mesmo assim, é improvável que o conjunto de suas universidades disponha de política e programas orientados para a promoção da internacionalização ativa exceção feita à Pontifícia Universidad Católica de Chile e Universidad de Chile. Para Bernasconi e Rojas (2003, p. 77-78), as razões que explicam a expressividade da internacionalização ativa no país não se devem à formulação de clara política por parte de universidades e Governo e sim às limitações financeiras: enquanto o país ganha divisas ao acolher estudantes internacionais, perde-as ao enviar. Contudo, os autores desconsideram que enquanto o país acolheu 1.966 estudantes em 2005 (Quadros 11), enviou 8.679, particularmente para os EUA (3.436) (Quadros 13) (UNESCO, 2007). Apesar de os autores assegurem que o Chile atraia, principalmente, estudantes estadunidense, dados do Recueil des Données Mondiales sur l'Éducation (2003, 2004, 2005) sinalizam que mais da metade dos acolhidos são latino-americanos. Para Sánchez (2005, p. 177), os fatores preponderantemente responsáveis pela contenção do crescimento da internacionalização passiva e ativa no país são as limitações no financiamento dos cursos internacionais (a) e o desconhecimento de um segundo idioma por parte de professores e estudantes (b). ${ }^{7}$

\begin{tabular}{|l|r|r|r|r|r|}
\hline \multicolumn{1}{|c|}{ Países } & \multicolumn{1}{|c|}{$\mathbf{2 0 0 1}$} & \multicolumn{1}{|c|}{$\mathbf{2 0 0 2}$} & \multicolumn{1}{c|}{$\mathbf{2 0 0 3}$} & \multicolumn{1}{c|}{$\mathbf{2 0 0 4}$} & \multicolumn{1}{c|}{$\mathbf{2 0 0 5}$} \\
\hline ARGENTINA & 3.255 & 3.343 & 3.261 & 3.261 & - \\
\hline BOLIVIA & - & - & 1.142 & 1.142 & - \\
\hline BRASIL & - & - & - & 1.260 & 1.246 \\
\hline CHILE & 3.477 & 4.883 & 5.211 & 5.211 & 1.966 \\
\hline COSTA RICA & - & - & - & 1.560 & 1.560 \\
\hline CUBA & - & - & - & 13.705 & 14.414 \\
\hline MÉXICO & - & - & - & 1.892 & - \\
\hline URUGUAI & 2.100 & 2.100 & 2.100 & 2.100 & - \\
\hline VENEZUELA & - & - & - & 2.472 & 2.472 \\
\hline
\end{tabular}

Quadro 11: Recepção de estudantes internacionais entre os países da América Latina e Caribe (2001-2005)

Fonte: Recueil de Données Mondiales sur l'Éducation. Institut de Statistique. UNESCO, 2003, 2004, 2005, 2006, 2007.

Quais são os países latino-americanos que acolhem estudantes internacionais e qual é a origem dos acolhidos pelas universidades da região? Cuba acolheu 11.867, Venezuela atraiu 2.060, Chile (1.088) e Costa Rica (1.015) receberam um pouco mais de mil estudantes, respectivamente. Possivelmente, o fato de Cuba ter investido em educação pública e de qualidade reconhecida nas áreas de Saúde e Educação influa sobre a captação de estudantes provenientes de todas

7 De acordo com Sánchez (2005, p. 177), 45\% das universidades tradicionais asseguram que os respectivos professores não têm domínio de uma segunda língua. 
as regiões do mundo - é um dos poucos países que promove a internacionalização ativa Sul-Sul (309 estudantes provenientes da Ásia e 1.668 da África). Ratificando o quanto os fatores econômicos e culturais pesam nas decisões relativas à mobilidade internacional de estudantes, chama-se atenção para 0 fato de a esmagadora maioria dos estudantes internacionais acolhidos pelas instituições da região serem latino-americanos: Brasil (364), Chile (1.088), Costa Rica (1.015), Cuba (11.867) e Venezuela (2.060) (Quadro 12).

Chama-se atenção, igualmente, para o desequilíbrio encontrado entre os números que expressam a internacionalização ativa e passiva na grande maioria dos países: enquanto a recepção de estudantes está restrita a poucos países segundo relatório de 2007, a cinco -, o envio de estudantes atinge praticamente todos eles. No Quadro 11 estão reunidos aqueles com matrícula mais expressiva - enquanto o Brasil acolhe 1.246 estudantes, emite 20.778; o Chile acolhe 1.966 e emite 8.679; a Venezuela acolhe 2.472 e emite 10.694 . Há relativo equilíbrio na emissão e recepção de estudantes internacionais na Costa Rica (acolhe 1.560, envia 1.716) e desequilíbrio positivo no caso de Cuba (acolhe 14.414 e envia 1.688) (Quadros 11 e 13). Reforçando a hegemonia norte-americana, destacase que o destino preferido pelos estudantes internacionais, provenientes dos países da América Latina e Caribe, que enviam mais de um mil acadêmicos ao ano para o exterior, com exceção de Cuba, é os EUA - dos 116.904 estudantes originários do México, Brasil, Colômbia, Peru, Venezuela, Argentina, Chile, Bolívia, Uruguai, Costa Rica e Cuba, 48678 foram para instituições estadunidenses, em 2005 (UNESCO, 2007). Entre alguns países espano-falantes (México, Colômbia, Peru, Venezuela, e Argentina), a Espanha aparece como o segundo destino preferido, correspondendo a 16001 estudantes - reforçando os resultados do estudo de Larsen e Vincent-Lancrin (2002) (Quadro 2).

A importância exercida pelos fatores culturais e econômicos mais uma vez é lembrada ao comparar os números relativos aos países preferidos pelos estudantes da região (Quadro 13) e os países responsáveis por mais de dois terços da matrícula internacional (Quadro 5): a Austrália e o Japão ainda não são rotas importantes entre os acadêmicos latino-americanos e isso decorre da distância geográfica e valor envolvido no transporte aéreo; sistemas de educação superior com pouca expressão mundial (mas acessíveis tanto em termos acadêmicos quanto culturais, geográficos e financeiros) fazem parte das principais escolhas dos estudantes latino-americanos: a Argentina, por exemplo, é a segunda escolha para bolivianos (709) e uruguaios (496), além de ser a terceira para chilenos (745); Cuba representa a segunda escolha para os costarriquenhos, a terceira para os venezuelanos e bolivianos, e a quarta para uruguaios, por exemplo. 


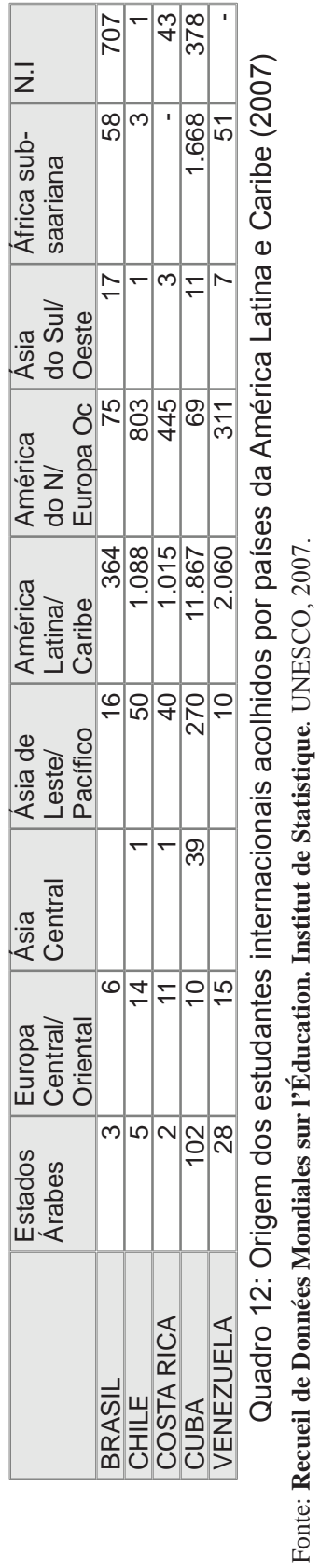

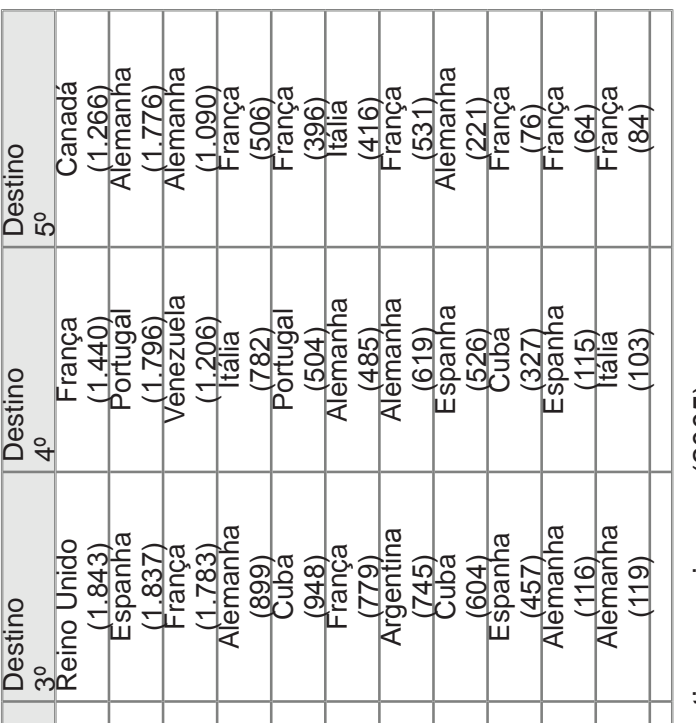

๙ซ

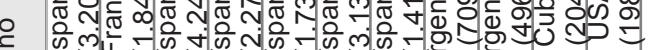

을

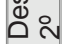

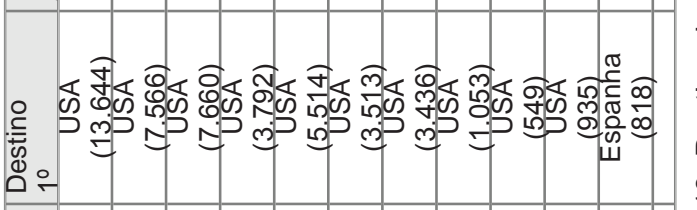

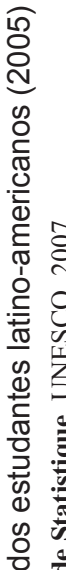

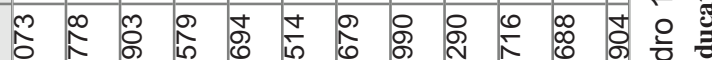
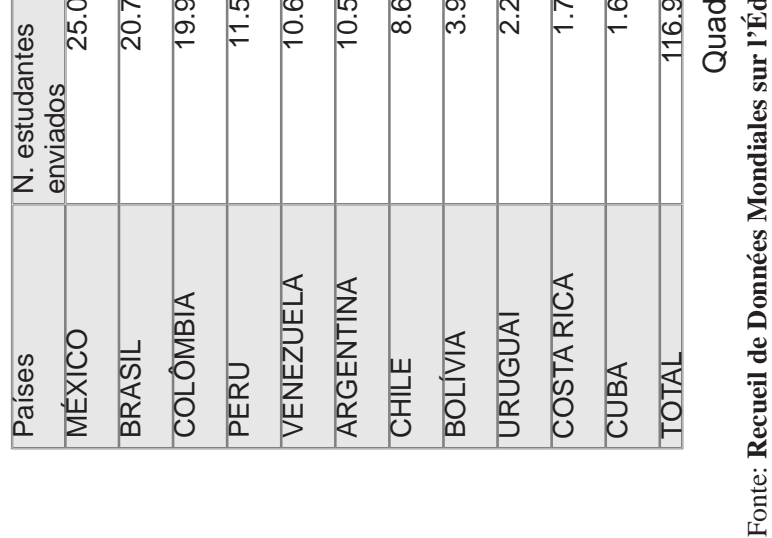
É curioso que em 2005, Portugal tenha acolhido apenas 1.796 dos 20.778 brasileiros em séjour de estudo no exterior, e tenha sido o quarto destino preferido, depois dos EUA, França e Espanha. É igualmente curioso que a Rússia esteja ausente do rol de cinco destinos preferidos pelos cubanos e os EUA se revelem a segunda rota preferida dos estudantes daquele país. Por último, chama atenção que o Reino Unido apareça apenas uma vez como preferência (é o terceiro destino dos estudantes mexicanos) quando é o segundo em matrícula internacional: 318.399, em 2005. (UNESCO, 2007)

$\mathrm{Na}$ Europa Ocidental não é raro que os países com elevada capacidade de atrair acadêmicos internacionais imponham anuidades mais elevadas aos estudantes externos à Comunidade Européia. No caso do Reino Unido, este valor varia de três a dez vezes o valor da anuidade, onerando sobremaneira famílias e governos dos países periféricos ou semi periféricos - "les étudiants étrangers hors de l'Union européenne paient au Royaume-Uni de 3 a 10 fois les droits d'inscription des étudiants nationaux" (FILIPPETTI, 2007, p. 17-19). Esta constatação faz Gabrielle Althoff (2008) (diretora do escritório DAAD Brasil) afirmar que, em oposição à Alemanha, países como a Grã-Bretanha, Austrália e Nova Zelândia atraem estudantes pela ótica da sustentabilidade financeira e não da cooperação.

\section{Considerações finais}

A mobilidade internacional de estudantes se revela em franco crescimento, inobstante, os estoques atuais de estudantes estrangeiros no mundo estão concentrados em poucas macro-regiões: América do Norte, Europa Ocidental, Leste Asiático e Austrália. Destaca-se que apenas sete países (EUA, Reino Unido, Alemanha, França, Austrália, Canadá e Japão) foram responsáveis por mais de dois terços da matrícula mundial (1.871.005 dos 2.728.480 estudantes). Os EUA são o principal território hospedeiro de estudantes internacionais do mundo: em 2005 as suas instituições acolheram 590128 acadêmicos, isso corresponde a um pouco mais do que a soma dos dois outros países mais importantes na recepção destes fluxos: Reino Unido (318.399) e Alemanha (259.797), que juntos perfizeram um total de 578.169 estudantes internacionais.

Na divisão mundial do trabalho universitário há um conjunto de países de segunda ordem de importância em termos de recepção de estudantes, todos localizados na Europa Ocidental - Reino Unido (318.399), Alemanha (259.797), e França (207.264) que juntos foram responsáveis pela recepção de 814.687 estudantes em 2005. Enquanto o Reino Unido acolhe, predominantemente, 
estudantes europeus, a França recebe estudantes provenientes da África. Considerando a representatividade da matrícula internacional ainda há um terceiro grupo: Austrália (207.264) e Canadá (132.982). Estes países despertam particular atenção pelo fato de em quatro anos, a população estudantil internacional ter praticamente duplicado (a Austrália passou de 105.764 para 207.264) ou triplicado (o Canadá passou de 40.033 para 132.982). Apesar de nos últimos anos os EUA, Reino Unido, Alemanha e França liderarem o ranking de recepção de acadêmicos internacionais, suas taxas de crescimento se revelam incomparáveis às encontradas na Austrália e Canadá.

Sublinha-se a explícita coincidência entre capacidade de captação de estudantes; pujança acadêmica, poder político e econômico: entre os sete países com maior capacidade de atração de estudantes, seis têm sistemas de educação superior consolidados, tanto em termos quantitativos, quanto qualitativos ${ }^{8}$; seis estão localizados no Hemisfério Norte; seis fazem parte do G7 (EUA, Canadá, Reino Unido, Alemanha, França e Japão); quatro são anglo-falantes (EUA, Reino Unido, Austrália e Canadá), e todos eles dispõem de uma política institucionalizada de atração de estudantes, e para tanto investem expressivos recursos na divulgação dos respectivos sistemas de educação superior.

A representatividade dos estudantes internacionais nos sistemas de educação superior de países com elevada capacidade de atração estudantil evidencia a importância que a educação multicultural vem ganhando e a necessidade de desenhar curricula ajustados à realidade emergente (articulando temas locais, regionais e universais sem desconsiderar a diversidade de línguas em contato): 23,3\% da população estudantil da Austrália é internacional; na Alemanha ela representa 12,5\%; na França, 11,7\%; no Reino Unido, 14,1\%; e nos EUA, 3,3\%. Sobre isso, vale a pena aprender com a experiência das universidades bilíngües - Université AboAkademi, Université d'Ottawa, Université de Fribourg, Université Libre de Bolzen, Université Européenne Viadrina, e Universidad de Puerto Rico. (PURSER, 2000)

Se até recentemente a mobilidade estudantil estava concentrada nos programas de pós-graduação stricto sensu, da década de 1990 em diante há crescente antecipação do projeto que envolve formação e vivência internacionais: quatro dos cinco países com forte capacidade de atração de estudantes internacionais matriculam um número próximo ou superior a $50 \%$ de estudantes interessados em cursar a graduação: Reino Unido (47\%), França (49,9\%), Austrália (56\%)

8 Enquanto os países que atraem maior número de estudantes internacionais apresentam expressivo número de instituições de educação superior classificadas no Academic Ranking of World Universities, (2006): $\mathrm{EUA}=168 ;$ Reino Unido $=42 ;$ Alemanha $=40 ;$ Japão $=34 ;$ Canadá $=23 ;$ França $=21$ e Austrália $=15$. 
e Alemanha $(69,5 \%)$ ampliando o raio de influência dos países hegemônicos sobre o sistema mundial de educação.

A presença do Estado fortalece e institucionaliza o processo de internacionalização da educação superior, independentemente de ele assumir características próprias da internacionalização ativa ou passiva - "dans les pays les plus dynamiques en matière d'accueil des étudiants étrangers - Grande-Bretagne, Australie, Allemagne - et très récemment l'Espagne, l'impulsion a été donée au plus haut niveau de l'État par la mise em place de grands programmes" (FILIPPETTI, 2007, p. 31). No contexto das políticas neoliberais, a preocupação reside em criar condições que favoreçam efetiva diversificação das fontes de financiamento da educação superior. Com isso, o Estado tende a assumir responsabilidades predominantemente regulatórias. Mas no contexto de governos que se empenham em formular políticas educacionais capazes de reforçar o caráter republicano da educação é possível identificar a emergência de iniciativas subordinadas ao fortalecimento de programas de internacionalização ativa de caráter contra-hegemônico, comprometidos com a inclusão social e a integração regional. Três projetos, em diferentes fases de formulação, se inscrevem nesta trilha: Universidade Federal da Integração Latino-americana (UNILA) (Foz do Iguaçu/Paraná), Universidade Federal de Integração LusoAfrobrasileira (UNILAB) (Redenção/Ceará), e Universidade Global da Bacia Amazônica (Santarém/Pará). A estes projetos se somam diversas iniciativas já consolidadas: Programa de Pós-Graduação em Integração da América Latina (PROLAM-USP/Brasil), Consejo Latinoamericano de Ciencias Sociales (CLACSO/vários países), Facultad Latinoamericana de Ciencias Sociales (FLACSO/vários países), Instituto Internacional para a Educação Superior na América Latina e no Caribe (IESALC/UNESCO), Associação de Universidades Grupo Montevidéu (AUGM/ vários países), Associação de Universidades da América Latina e Caribe para Integração, entre outros (CHERMANN, 1999). A importância acadêmica, cultural, social e política destes projetos justificam a ampliação/aprofundamento da pesquisa em andamento e a elaboração de texto específico.

\section{Referências}

ALTHOFF, Gabrielle. Formas de financiamento para a mobilidade de estudantes e professores: ações e perspectivas, Mesa 3. FÓRUM BRASILEIRO DE EDUCAÇÃO INTERNACIONAL, 1, São Paulo, 2008. 
BALLATORE, Magali; BLÖSS, Thierry. Le sens caché de la mobilité des étudiants Erasmus. In: DERVIN, Fred; BYRAM, Michel. (Dir.). Échanges et mobilités académiques. Paris: L'Harmattan, 2008.

BANQUE MONDIAL; ORGANIZATION DE COOPÉRATION ET DE DÉVELOPPEMENT ÉCONOMIQUES. L'enseignement supérieur en Amérique latine. Paris: Bird/OCDE, 2005.

BERNASCONI, Andrés; ROJAS, Fernando. Informe sobre la educación en Chile: 1980-2003. Instituto Internacional para la Educación Superior en América latina y el Caribe, [s.1.], ago. 2003.

BRANDÃO, Carlos Antônio. Industrialização Brasileira: desafios da competitividade e a necessidade de uma política ativa. Economia Ensaios, Uberlância, v. 8, n. 2, p. 51-68, 1994.

BRANDÃO, Gildo Marçal. Teoria política a partir do Sul da América? Filosofia política contemporânea: controvérsias sobre civilização, império e cidadania. Buenos Aires: CLACSO; São Paulo: FLCH/USP, 04/2006.

BROUILLETTE, Véronique; FORTIN, Nicole. La mondialisation néolibérale et l'enseignement supérieur. 01/2004 (mimeo).

CAMPUSFRANCE. Les étudiants internationaux: chiffres clés. França Flash, Paris, n.65, 10 out. 2008.

CHARLE, Christophe et al. Ensino superior: o momento crítico. Educação \& Sociedade, Campinas, v. 25, n. 88, Especial, p. 961-975, out. 2004.

CHERMANN, Luciane de Paula. Cooperação internacional e universidade: uma nova cultura no contexto da globalização. São Paulo: Educ, 1999.

DALE, Roger. Globalização e educação: demonstrando a existência de uma 'cultura educacional mundial comum' ou localizando uma 'agenda globalmente estruturada para a Educação. Educação \& Sociedade, Campinas, v. 25, n. 87, p. 423-460, maio/ago. 2004.

FIEMEYER, Jean-Claude. Les enseignements supérieures das le monde, échatement et effervescence. Paris: ADICE-Édition, 2004.

FILIPPETTI, Aurélie. Action extérieure de l'État rayonnement culturel et scientifique. France: Assemblée Netionale, n. 277, 11 out.2007.

IANNI, Octavio. A sociedade global. 12. ed. Rio de Janeiro: Civilização Brasileira, 2005. 
KNIGHT, Jane. Modèle d'internationalisation ou comment faire face aux réalités et enjeux nouveaux. In: OCDE. L'enseignement supérieur en Amérique latine: la dimension internationale. Paris: Organization de Coopération et de Développement Économique, 2005. p. 11-45.

LARSEN, Kurt; VINCENT-LANCRIN, Stéphan. Le commerce international de services d'éducation: Est-il bom? Est-il méchant? Politiques et gestion de l'enseignement supérieur. dec. 2002.

LOURENÇO, Erica Fernanda Vilaça. A internacionalização do setor siderúrgico: um estudo sobre as empresas líderes brasileiras. 2006. Monografia. Faculdade de Ciências e Letras. Departamento de Economia. UNESP/Araraquara, 2006.

OECD - ORGANIZATION FOR ECONOMIC COOPERATION AND DEVELOPMENT. Oecd science, technology and industry: scoreboard 2007 edition.

. Education at a glance. 2006a.

. Higher education: quality, equity and efficiency. Background report. Athens, 2006b.

. Enseignement supérieur: internationalization et commerce. Paris: OCDE, 2004.

PURSER, Lewis. L'université bilingüe: réflexions générales sur ses origines, sa mission et son fonctionnement. Unesco/Cepes: Enseignement Supérieur en Europe. VXXV, n. 4, p. 07-18, 2000.

RIDDER-SYMOENS, Hilde. A mobilidade. In: RÜEGG, Walter (Coord.). Uma história da universidade na Europa. As universidades na europa moderna: 1500-1800. Lisboa: Imprensa Nacional, 2002. p. 403-432. v. II.

ROSELINO, José Eduardo; DIEGUES, Antônio Carlos. A constituição de redes produtivas globais e a internacionalização da indústria de software.

In: ENCONTRO NACIONAL DA ASSOCIAÇÃO NACIONAL DE PÓS-GRADUAÇÃO E PESQUISA EM ADMINISTRAÇÃO, 30., 2006, Salvador. Anais do... Salvador, 2006.

ROSSATO, Ricardo. Universidade: nove séculos de história. Passo Fundo: UPF, 1998.

SÁNCHEZ, Carlos Ramires. L'internationalisation de l'enseignement au Chili. In: L'ENSEIGNEMENT SUPÉRIEUR EN AMÉRIQUE LATINE: 
la dimension internationale. Paris: Banque Mondial; OCDE, 2005, p.157186. Disponível em: <http://www.eca.usp.br/alaic/trabalhos2004/gt4/ verlanesantos.htm>. Acesso em: 28 set. 2008.

SANTOS, Boaventura Sousa. Os processos da globalização. In: SANTOS, Boaventura Sousa (Org.). Globalização: fatalidade ou utopia? 2. ed. Porto: Afrontamento, 2002. p. 31-106.

SANTOS, Milton. Por uma outra globalização: do pensamento único à consciência universal. 13. ed. Rio de Janeiro: Record, 2006.

SANTOS, Verlane Aragão. Regulamentação do macro-setor das comunicações no Brasil e a convergência audiovisual, telecomunicações, informática. 2004. Disponível em: <http://www.eca.usp.br/alaic/ trabalhos2004/gt4/verlanesantos.htm>. Acesso em: 28 set. 2008.

TEODORO, António. Globalização e educação: políticas educacionais e novos modos de governação. São Paulo: Cortez, 2003.

UNESCO/IAU. Internacionalização da educação superior: tendências e desenvolvimentos desde 1998. In: EDUCAÇÃO SUPERIOR: REFORMAS, MUDANÇAS E INTERNACIONALIZAÇÃ̃, 2003, Brasília. Anais... Brasília: UnescoBr., 2003. p.151-194. Disponível em: <http://www.unesco. org.br/publicacoes/livros/educasuperior>. Acesso em: 08 set. 2008.

UNESCO/Institut de Statistique. Recueil des données mondiales sur l'éducation: statistiques comparées sur l'éducation dans le monde, 2003; 2004; 2005; 2006; 2007.

VELLOSO, Jacques. Pós-graduação: egresso, trabalho e formação no país e no exterior. In: STEINER, João E.; MALNIC, Gerhard (Orgs). Ensino superior: conceito e dinâmica. São Paulo: USP, 2006. p. 177-242.

VON HUMBOLDT, Wilhelm von. Sobre a organização interna e externa das instituições científicas superiores em Berlim. In: ROCHA, João C. de Castro. Um mundo sem universidades? Rio de Janeiro: UERJ, 1997. p. 79-100.

VUILLETET, Guillaume. Comparaison internationale des politiques d'accueil des étudiants étrangers: quelles finalités? Quelles moyens? Paris: Conseil Économique et Social, n. 24, 2005. 